\title{
Posterior Approach Alone Versus Combined Anterior and Posterior Approach in the Management of Vertebral Tuberculosis
}

\author{
Mehmet DEMIREL ${ }^{1}$, Turgut AKGUL ${ }^{1}$, Tuna PEHLIVANOGLU ${ }^{1}$, Gokhan KARADEMIR ${ }^{1}$, Serkan BAYRAM ${ }^{1}$, \\ Fatih DIKICl${ }^{2}$, Cuneyt SAR ${ }^{1}$
}

${ }^{1}$ Istanbul University, Istanbul School of Medicine, Department of Orthopaedics and Traumatology, Istanbul, Turkey

${ }^{2}$ Acibadem Mehmet Ali Aydinlar University, Department of Orthopaedics and Traumatology, Istanbul, Turkey

Corresponding author: Mehmet DEMIREL dr88.mehmet.demirel@gmail.com

\section{ABSTRACT}

AIM: To compare posterior surgery alone versus combined anterior and posterior surgery for the management of spinal tuberculosis.

MATERIAL and METHODS: Data from 31 consecutive patients who underwent surgery for spinal tuberculosis were analyzed retrospectively. Patients were divided into two groups as group A (posterior surgery alone) or group B (combined anterior and posterior surgery), and groups were compared in terms of invasiveness of the procedure, spinal deformity, fusion, neurological status, and postoperative complications.

RESULTS: Group A included 16 patients (mean age: 56 years, range: 29-75) with a mean follow-up period of 29 months (range 12-60) while group B included 15 patients (mean age: 60 years, range: $35-73$ ) with a mean follow-up period of 28 months (range 12-60). Procedurally, average operation time and mean length of hospitalization were shorter, and mean blood loss was lower in group A $(p<0.05)$ compared to group B. Postoperative bone fusion took significantly $(p<0.05)$ longer time in group A $(10.5 \pm 2.1$ months)than in group B $(9.3 \pm 3.1$ months), and all patients with a neurological deficit recovered completely during the postoperative period. No significant differences were observed between two groups with respect to postoperative complications ( $p>0.05$ ).

CONCLUSION: Combined anterior-posterior surgery may not be required for treating vertebral tuberculosis as posterior surgery alone appears to be sufficient.

KEYWORDS: Tuberculosis, Pott's disease, Spine, Treatment, Surgery, Posterior approach, Combined approach

\section{INTRODUCTION}

$\mathrm{T}$ Tuberculosis of the spine or Pott's disease is the most common and hazardous type of bone tuberculosis that gives rise to several challenges such as kyphotic deformity, neurological deficits, and compression of the spinal cord if diagnosis and treatment are delayed (29). According to the World Health Organization, tuberculosis is the most common specific cause of mortality due to infection worldwide (20). Even though it is relatively rare in the United States and in western Europe (9), Turkey has shown an increasing trend in tuberculosis incidence in recent years $(2,26)$.

Anti-tuberculosis chemotherapy is the mainstay for the management of spinal tuberculosis; however, surgical treatment occupies a conspicuous place in achiveving successful outcomes, and a variety of surgical protocols have been utilized to treat this disease, with each procedure having both advantages and disadvantages $(23,26)$. The anterior approach, which provides direct visual access during excision of the lesion, is
Mehmet DEMIREL $\quad$ (1) : 0000-0003-1131-7719

Turgut AKGUL (1) : 0000-0002-0704-3797

Tuna PEHLIVANOGLU (D) : 0000-0001-8886-7538
Gökhan KARADEMIR

Serkan BAYRAM

Fatih DIKICl
Cüneyt SAR (10) : 0000-0002-6920-1199

(1) : 0000-0001-7651-1200

(D) : 0000-0003-2681-0098 
strongly recommended by many authors $(7,15,22)$; however, the efficacy of these procedures is not clearly established (6), as some authors have inferred that the posterior approach prevents some complications seen with the anterior approach (12). Nonetheless, whether through a posterior alone or the combined approach, both aim to prevent progressive deformity and neurological dysfunction during the management of vertebral tuberculosis $(30,32,33)$.

In our study, clinical outcomes among patients with spinal tuberculosis who underwent surgery using the posterior approach alone or the combined anterior and posterior surgery were investigated and the study aimed to compare the efficacy of posterior surgery alone versus the combined anterior and posterior approach for the management spinal tuberculosis.

\section{MATERIAL and METHODS}

\section{Patients}

From January 1999 to June 2014, 60 consecutive patients with a diagnosis of spinal tuberculosis underwent the posterior surgery alone or the combined anterior and posterior surgery at our tertiary care facility. With an emphasis on postoperative radiological examination outcomes, inclusion criteria for this study were presence of a Type A spinal deformity according to the Rajasekaran classification (21) (Table I); thus patients with Type $B(n=20)$ or Type $C(n=9)$ spinal deformites were excluded and 31 patients with Type $A$ deformites alone were included. Next, they were divided into two groups as group A (posterior surgery alone) and group B (combined anterior and posterior surgery). We retrospectively analyzed the clinical outcomes in each group.

Spinal tuberculosis was diagnosed based on clinical presentation, radiological findings in the spine [plain radiographs, computed tomography (CT), magnetic resonance imaging (MRI)] (Figures 1-3), and hematological and pathological assessments. Diagnostic verification depended on the analysis of surgical biopsy specimens, acid-fast staining, bacterial cultures, or polymerase chain reaction.

Clinical presentation in most cases was characterized by back pain, night sweats, weight loss $(n=14)$, difficulty walking due to the neurological deficits $(n=9)$, and kyphotic deformity $(n=8)$. Furthermore, the average symptomatic period was 9 months (range: 3-45 months).

\section{Operative Technique}

Under general anesthesia, patients in group A were placed prone on a padded spinal operating frame, and based on preoperative presentation and imaging, transpedicular screws were inserted under fluoroscopic guidance. After screw placement, a titanium rod was temporarily placed on the contralateral side to prevent spinal cord injury provoked by instability of the spine during decompression and focal debridement. Subsequently, to expose the intervertebral space, a hemilaminectomy, a costotransversectomy, and a pediculectomy were performed on the same side. After debridement of the destroyed disk and the collapsed vertebrae, the paravertebral or psoas abscess (if present) was removed. To reconstruct the affected vertebrae, a titanium mesh cage filled with autogenous bone or appropriate autogenous struts obtained from the fibula was applied.

In group B patients, a two-stage procedure was performed, wherein, in the first stage, the anterior approach was used to obtain both appropriate distraction of the intervertebral space and sufficient debridement of the involved vertebrae. After decompression, the anterior defect area was filled with a titanium mesh cage or autogenous struts. In the second stage of the procedure, the pedicle screw and the titanium rod were inserted after standard posterior exposure, as described above.

\section{Clinical Outcomes}

\section{Invasiveness of The Procedures}

To assess the invasiveness of each approach, variables such as intraoperative blood loss, operation time, and lenght of hospitalization were analyzed.

\section{Spinal Deformity and Fusion}

Kyphosis was observed in all patients and kyphotic deformity was measured as the angle between upper and lower surfaces of the collapsed vertebral levels ona lateral plain X-ray image of the spine. This measurement was obtained before and after the first procedure, and at the last follow-up visit. Likewise, to assess fusion, a plain radiograph was used in patients with a fibular autogenous graft; however, CT imaging was preferred in patients with titanium mesh cages to accurately visualize metallic artifacts. Additionally, bone fusion was verified by two different spine surgeons according to modified criteria for radiological fusion, as described by Lee et al. (13) (Table II).

Table I: Rajasekaran Classification of Spinal Tuberculosis (21)

\begin{tabular}{lcccc}
\hline $\begin{array}{l}\text { Type of } \\
\text { restabilization }\end{array}$ & Anterior column contact & $\begin{array}{c}\text { Initial loss of } \\
\text { vertebral body }\end{array}$ & Facet Joint & Final deformity \\
\hline Type A & Wide & $<0.75$ & Intact & $\begin{array}{c}\text { Spontaneous improvement, } \\
\text { if increase }<10^{\circ}\end{array}$ \\
\hline Type B & Point contact & $0.75-1.5$ & $\begin{array}{c}\text { Subluxed or single level } \\
\text { dislocation }\end{array}$ & $<60^{\circ}$ \\
\hline Type C & $\begin{array}{c}\text { By } 90^{\circ} \text { sagittal rotation of } \\
\text { superior vertebrae }\end{array}$ & $>1.5$ & Dislocation of two or more & Can be more than $100^{\circ}$ \\
\hline
\end{tabular}






Figure 1: Lateral (left) and anteroposterior (right) radiographs of the spine show $\mathrm{T} 11, \mathrm{~T} 12$, and L1 involvement of vertebral tuberculosis.

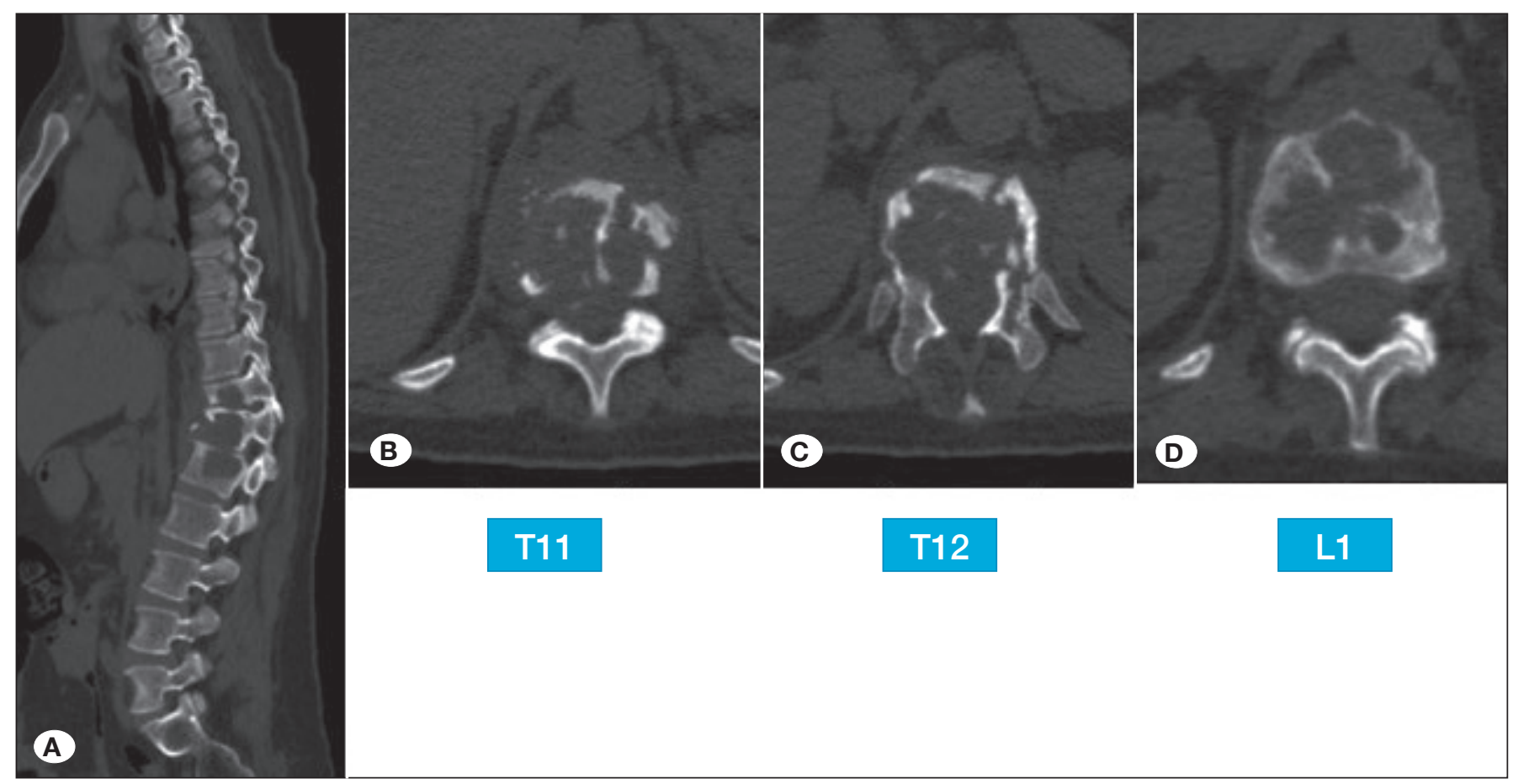

Figure 2: Sagittal (A) and axial CT scans display T11 (B), T12 (C), and L1 (D) involvement due to vertebral tuberculosis. 


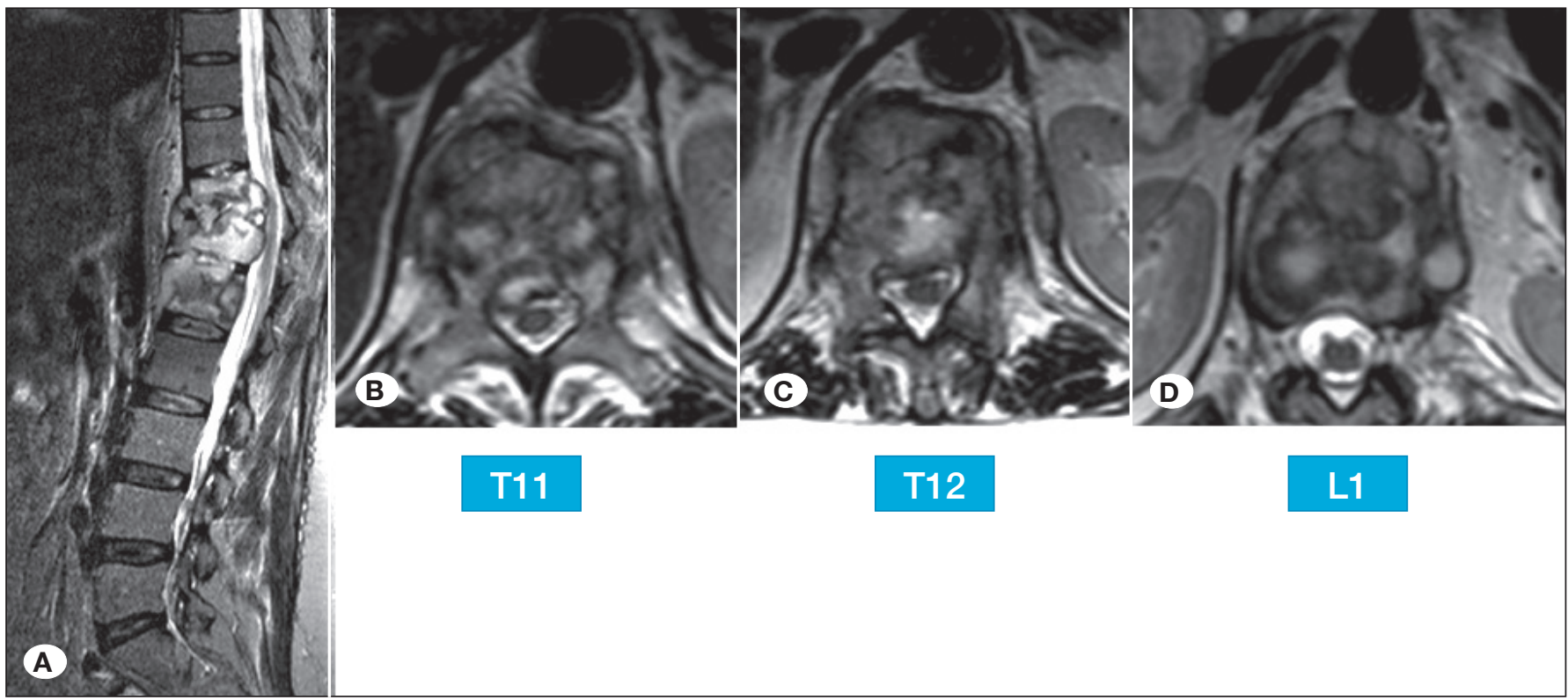

Figure 3: Sagittal (A) and axial MRI scans display T11 (B), T12 (C), and L1 (D) involvement due to vertebral tuberculosis.

\section{Laboratory Findings}

Infection was monitored using serum C-reactive protein (CRP) and erythrocyte sedimentation rate (ESR) and these were measured preoperatively and at final follow-up.

\section{Neurological Status}

Neurological improvement was assessed using the American Spinal Injury Association impairment (ASIA) scale, both preoperatively and at the final visit.

\section{Postoperative Complications:}

Intraoperative and postoperative complications were evaluated based on radiographs and surgical reports of each patient.

\section{Postoperative Care}

The drain was removed earlier if discharge was less than 50 $\mathrm{ml} / 24$ hours. Patients were allowed to ambulate approximately 24 hours after the procedure. An anti-tuberculosis regimen of isoniazid $300 \mathrm{mg}$, rifampisin $450 \mathrm{mg}$, ethambutol $1200 \mathrm{mg}$, and pyrazinamide $1500 \mathrm{mg}$ was prescribed to all patients for 12-18 months postoperatively. Thoraco-lumbo-sacral orthosis was also provided for 4-6 months. All patients were monitored at 3, 6, 9, and 12 months after the procedure, and subsequently, once a year. At each follow-up visit, X-rays, and laboratory indices, including complete blood count, ESR, $\mathrm{CRP}$, and hepatic function tests, were evaluated.

\section{Statistical Analysis}

Except for postoperative complications, paired t test was used to compare parameters between groups while the Pearson's Chi-squared test was used to compare postoperative complications between the two groups. The statistical software package SPSS 20.0 (IBM Corp, 2011, Armonk, New York) was used for all analyses. Differences were considered significant if $p<0.05$.
Table II: Modified Radiological Fusion Criteria of Lee et al. (13)

\section{Definitive Fusion}

Definitive bony trabeculae bridging across the graft host interface.

No movement (less than $3^{\circ}$ ) on dynamic radiographs and no gap at interface.

\section{Probable Fusion}

No definitive trabeculae crossing the graft host interface, but no detectable motion and identifiable gap at the interface.

\section{Possible Pseudoarthrosis}

No definitive trabeculae crossing the graft host interface, but no detectable motion but identifiable gap at the interface.

\section{Definitive Pseudoarthrosis}

No definitive trabeculae bone, definitive gap, and movement more than $3^{\circ}$ at the interface.

\section{RESULTS}

Table III and IV demostrate demographic, clinical, and radiological features of patients in Group A and Group B, respectively, and Table $\mathrm{V}$ shows the comparison of clinical outcomes between the two groups. All cases of spinal tuberculosis included in the study were considered as cured based on laboratory values (CRP, ESR) and radiological evidence of fusion on CT and plain radiographs (Figures 4 and 5).

Group A included 16 patients (nine males and seven females), with a mean age of 56 years at admission (range, 29 to 75). The average duration of follow-up in group A was 29 months (range: 12-60). Group B included 15 patients (seven men and eight women), with a mean age of 60 years at admission 
Table III: Demographic, Clinical and Radiological Features of Patients in Group A

\begin{tabular}{|c|c|c|c|c|c|c|c|c|c|c|c|c|}
\hline \multirow{2}{*}{ Case no } & \multirow{2}{*}{$\begin{array}{l}\text { Age/ } \\
\text { Gender }\end{array}$} & \multirow{2}{*}{ Level } & \multirow{2}{*}{$\mathrm{FU}(\mathrm{m})$} & \multicolumn{3}{|c|}{ Kyphosis Angle ( ${ }^{\circ}$ ) } & \multicolumn{2}{|c|}{ ASIA } & \multicolumn{2}{|c|}{ CRP } & \multicolumn{2}{|c|}{ ESR $(\mathrm{mm} / \mathrm{h})$} \\
\hline & & & & Preop & Postop & Final & Preop & Final & Preop & Postop & Preop & Postop \\
\hline 1 & $71 / F$ & T12,L1-L2 & 60 & 35 & 29 & 30 & A & E & 35 & 10 & 68 & 3 \\
\hline 2 & $67 / F$ & T10-L2 & 50 & 38 & 32 & 33 & $\mathrm{~B}$ & $\mathrm{E}$ & 32 & 9 & 65 & 7 \\
\hline 3 & $51 / \mathrm{M}$ & $\mathrm{T} 6-\mathrm{T} 7$ & 40 & 41 & 6 & 7 & C & D & 45 & 4 & 55 & 5 \\
\hline 4 & $50 / F$ & T8-T10 & 30 & 35 & 13 & 14 & $\mathrm{C}$ & $\mathrm{D}$ & 46 & 3 & 59 & 6 \\
\hline 5 & $65 / \mathrm{M}$ & T8-T10 & 35 & 55 & 16 & 16 & C & $E$ & 58 & 1 & 57 & 8 \\
\hline 6 & $67 / \mathrm{M}$ & L3 & 12 & 12 & 6 & 6 & E & E & 75 & 5 & 80 & 9 \\
\hline 7 & 73/M & T9-T10 & 12 & 60 & 20 & 22 & E & E & 54 & 2 & 57 & 10 \\
\hline 8 & $72 / \mathrm{F}$ & $\mathrm{T6}-\mathrm{T} 7$ & 24 & 34 & 16 & 17 & $\mathrm{D}$ & E & 21 & 10 & 49 & 9 \\
\hline 9 & $58 / \mathrm{M}$ & L4-L5 & 24 & 50 & 15 & 16 & C & $E$ & 45 & 12 & 40 & 8 \\
\hline 10 & $45 / \mathrm{M}$ & $\mathrm{T} 10-\mathrm{T} 12$ & 16 & 25 & 5 & 6 & D & $E$ & 65 & 9 & 67 & 3 \\
\hline 11 & $29 / F$ & T6-T7 & 18 & 28 & 10 & 11 & E & E & 55 & 12 & 50 & 8 \\
\hline 12 & $46 / F$ & T7-Т8-T9 & 14 & 30 & 9 & 10 & D & E & 65 & 10 & 80 & 7 \\
\hline 13 & $75 / \mathrm{M}$ & T10-L2 & 55 & 35 & 12 & 15 & $\mathrm{C}$ & $E$ & 45 & 5 & 50 & 5 \\
\hline 14 & $31 / \mathrm{M}$ & T5-T6-T7 & 35 & 15 & 5 & 6 & E & E & 25 & 8 & 60 & 10 \\
\hline 15 & $49 / F$ & T9-T10 & 25 & 5 & 3 & 3 & $E$ & $E$ & 45 & 3 & 67 & 9 \\
\hline 16 & $50 / \mathrm{M}$ & T6-T7 & 14 & 25 & 7 & 8 & $\mathrm{E}$ & $\mathrm{E}$ & 45 & 2 & 78 & 5 \\
\hline
\end{tabular}

F: Female, M: Male, T: Thoracic, L: Lumbar, FU: Follow-up, m: Months, Preop: Preoperative, Postop: Postoperative, ASIA: American Spinal Injury Association impairment, CRP: C-reactive protein, ESR: Erythrocyte sedimentation rate.

Table IV: Demographic, Clinical and Radiological Features of Patients in Group B

\begin{tabular}{|c|c|c|c|c|c|c|c|c|c|c|c|c|}
\hline \multirow{2}{*}{ Case no } & \multirow{2}{*}{$\begin{array}{l}\text { Age/ } \\
\text { Gender }\end{array}$} & \multirow{2}{*}{ Level } & \multirow{2}{*}{ FU (m) } & \multicolumn{3}{|c|}{ Kyphosis Angle ( ${ }^{\circ}$ ) } & \multicolumn{2}{|c|}{ ASIA } & \multicolumn{2}{|c|}{ CRP } & \multicolumn{2}{|c|}{$\operatorname{ESR}(\mathrm{mm} / \mathrm{h})$} \\
\hline & & & & Preop & Postop & Final & Preop & Final & Preop & Postop & Preop & Postop \\
\hline 1 & $68 / F$ & T9-T11 & 60 & 35 & 12 & 13 & $\mathrm{C}$ & $E$ & 56 & 9 & 48 & 5 \\
\hline 2 & $65 / F$ & L2-L1 & 55 & 45 & 10 & 12 & $\mathrm{D}$ & $\mathrm{E}$ & 32 & 8 & 56 & 8 \\
\hline 3 & $50 / \mathrm{M}$ & T8-T11 & 45 & 33 & 15 & 16 & $\mathrm{C}$ & E & 50 & 6 & 67 & 7 \\
\hline 4 & $50 / \mathrm{M}$ & L1-L2 & 40 & 30 & 10 & 11 & $\mathrm{E}$ & E & 46 & 2 & 54 & 10 \\
\hline 5 & $35 / F$ & $\mathrm{~T} 12-\mathrm{L} 1$ & 24 & 11 & 2 & 5 & $E$ & E & 58 & 1 & 65 & 6 \\
\hline 6 & $71 / \mathrm{F}$ & $\mathrm{T} 10-\mathrm{T} 11$ & 24 & 15 & 5 & 5 & $\mathrm{E}$ & $E$ & 75 & 6 & 90 & 13 \\
\hline 7 & $71 / \mathrm{F}$ & T10-T11-T12 & 12 & 45 & 14 & 15 & A & $\mathrm{E}$ & 54 & 5 & 48 & 4 \\
\hline 8 & $49 / M$ & T12-L2 & 12 & 5 & 2 & 3 & $E$ & E & 25 & 8 & 45 & 5 \\
\hline 9 & $58 / \mathrm{M}$ & T7-8 & 15 & 34 & 9 & 10 & $E$ & E & 45 & 16 & 67 & 11 \\
\hline 10 & $68 / F$ & $\mathrm{~T} 10-\mathrm{T} 11$ & 16 & 3 & 2 & 4 & $E$ & $E$ & 65 & 9 & 76 & 10 \\
\hline 11 & $72 / \mathrm{M}$ & T12-L1 & 18 & 26 & 10 & 11 & $\mathrm{E}$ & $E$ & 55 & 12 & 56 & 4 \\
\hline 12 & $73 / \mathrm{F}$ & T7-T9 & 44 & 28 & 15 & 16 & $E$ & $\mathrm{E}$ & 70 & 8 & 98 & 9 \\
\hline 13 & $54 / \mathrm{M}$ & T9-T10 & 24 & 25 & 8 & 8 & $E$ & E & 45 & 4 & 64 & 7 \\
\hline 14 & $63 / \mathrm{M}$ & T8-T10 & 23 & 24 & 11 & 13 & $E$ & E & 25 & 9 & 43 & 9 \\
\hline 15 & $58 / F$ & T6-T9 & 22 & 30 & 9 & 10 & $E$ & $E$ & 45 & 2 & 57 & 5 \\
\hline
\end{tabular}

F: Female, M: Male, T: Thoracic, L: Lumbar, FU: Follow-up, m: Months, Preop: Preoperative, Postop: Postoperative, ASIA: American Spinal Injury Association impairment, CRP: C-reactive protein, ESR: Erythrocyte sedimentation rate. 
Table V: The Clinical Outcomes in Group A vs. Group B

\begin{tabular}{|c|c|c|c|}
\hline & $\begin{array}{c}\text { Group A }(n=16) \\
\text { Mean } \pm \text { SD }\end{array}$ & $\begin{array}{c}\text { Group B }(n=15) \\
\text { Mean } \pm \text { SD }\end{array}$ & $\mathbf{p}$ \\
\hline Operation time (minutes) & $180.5 \pm 21.5$ & $361.3 \pm 61.3$ & 0.000 \\
\hline Hospital stay (days) & $16.8 \pm 4.8$ & $27.3 \pm 3.4$ & 0.000 \\
\hline Blood loss (mL) & $463 \pm 52$ & $573 \pm 57$ & 0.000 \\
\hline \multicolumn{4}{|l|}{ Kyphotic angle $\left(^{\circ}\right)$} \\
\hline Preoperative & $32.6 \pm 14.8$ & $25.9 \pm 12.7$ & 0.186 \\
\hline Postoperative & $16.1 \pm 9.4$ & $10.8 \pm 8.3$ & 0.292 \\
\hline Final visit & $16.9 \pm 9.5$ & $12.3 \pm 9.3$ & 0.155 \\
\hline Correction of the angle & $16.5 \pm 13.6$ & $14.4 \pm 10.2$ & 0.322 \\
\hline Loss of the correction & $0.8 \pm 0.5$ & $1.4 \pm 1.4$ & 0.104 \\
\hline Fusion time (months) & $10.5 \pm 2.1$ & $9.3 \pm 3.1$ & 0.012 \\
\hline Fusion rate (\%) & 93.75 & 100 & \\
\hline Follow-up time (months) & $30(12-60)$ & $35(12-66)$ & 0.990 \\
\hline ASIA scale (Preoperative) & $\mathrm{n}$ & $\mathrm{n}$ & \\
\hline $\begin{array}{l}A \\
B \\
C \\
D\end{array}$ & $\begin{array}{l}1 \\
1 \\
5 \\
3 \\
\end{array}$ & $\begin{array}{l}1 \\
0 \\
2 \\
1 \\
\end{array}$ & \\
\hline \multicolumn{4}{|l|}{ ASIA scale (Final follow-up) } \\
\hline $\begin{array}{l}A \\
B \\
C \\
D\end{array}$ & $\begin{array}{l}0 \\
0 \\
0 \\
2\end{array}$ & $\begin{array}{l}0 \\
0 \\
0 \\
0\end{array}$ & \\
\hline $\mathrm{ESR}(\mathrm{mm} / \mathrm{h})$ & Mean \pm SD & Mean \pm SD & \\
\hline Preoperative & $65.8 \pm 10.5$ & $66.8 \pm 11.8$ & 0.859 \\
\hline Final visit & $7.8 \pm 3.1$ & $8.2 \pm 4.2$ & 0.560 \\
\hline \multicolumn{4}{|l|}{$\mathrm{CRP}(\mathrm{mg} / \mathrm{L})$} \\
\hline Preoperative & $47.2 \pm 14.6(21-75)$ & $48.1 \pm 14.6(25-75)$ & 0.641 \\
\hline Final visit & $6.5 \pm 3.8(1-12)$ & $6.7 \pm 4.2(1-16)$ & 0.756 \\
\hline Complications & $\mathrm{n}$ & $\mathrm{n}$ & \\
\hline Duramater injury & 1 & 1 & \\
\hline Nonunion & 2 & - & \\
\hline Screw pull out & - & 1 & \\
\hline Rod breakage & 1 & - & \\
\hline Superficial wound infection & 1 & 2 & \\
\hline Hemothorax & - & 2 & \\
\hline Pleural Effusion & - & 3 & \\
\hline
\end{tabular}

ASIA: American Spinal Injury Association impairment, ESR: Erythrocyte sedimentation rate, CRP: C-reactive protein. 

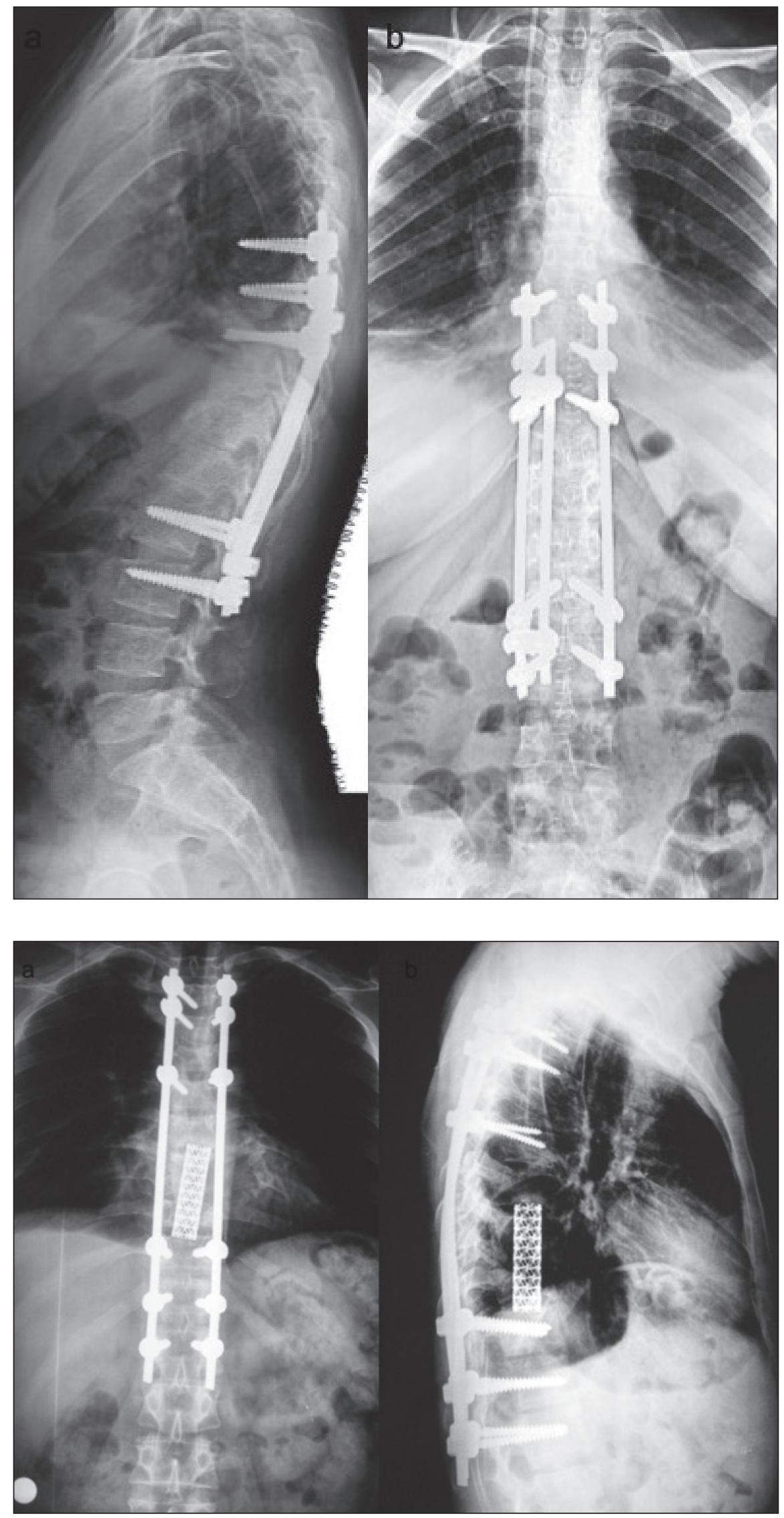

Figure 4: Postoperative lateral (left) and anteroposterior (right) radiographs of the spine demonstrate posterior spinal instrumentation with rods and pedicle screws.
Figure 5: Postoperative anteroposterior (left) and lateral (right) radiographs illustrate posterior spinal instrumentation and titanium mesh cage filled with autogenous bone. 
(range: $35-73$ ). The average duration of follow-up in group B was 28 months (range 12 to 60). The treatment groups were comparable in terms of above demographic characteristics.

The region of the spine involved was similar in group $A$ and group B; specifically, in group $A$, it was the thoracic region in 11 patients, the thoracolumbar region in three patients, and the lumbar region in two patients, while in group $B$ it was the thoracic region in 10 , the thoracolumbar region in 3 , and the lumbar region in 2 patients.

\section{Invasiveness of the Procedures}

A comparison of invasiveness between the two approaches showed that average operation time and the mean length of hospitalization were shorter, and that mean blood loss was lower in group $A$ than in group $B(p<0.05$ for all parameters). Specifically, average operation time was $180.5 \pm 21.5$ minutes in group $A$ and $361.3 \pm 61.3$ minutes in group $B$. The mean length of hospitalization was $16.8 \pm 4.8$ days in group $A$ and $27.3 \pm 3.4$ days in group $B$. Mean intraoperative blood loss was $463 \pm 52 \mathrm{~mL}$ in group $A$ and $573 \pm 57 \mathrm{~mL}$ in group $B$.

\section{Spinal Deformity and Fusion}

In group A patients, the kyphotic angle decreased from $32.6^{\circ}$ preoperatively to $25.9^{\circ}$ postoperatively, yielding a mean correction angle of $16.5^{\circ} \pm 13.6^{\circ}$, while in group $B$, it decreased from $25.9^{\circ} \pm 12.7^{\circ}$ preoperatively to $10.8^{\circ} \pm 8.3^{\circ}$ postoperatively, thus providing a mean correction angle of $14.4^{\circ} \pm 10.2^{\circ}$. At final follow-up, while group $A$ showed a mean kyphotic angle of $16.9^{\circ} \pm 9.5^{\circ}$, it was $12.3^{\circ} \pm 9.3^{\circ}$ in group $B$; thus, loss of correction was $0.8^{\circ} \pm 0.5^{\circ}$ in group $A$ and $1.4^{\circ} \pm$ $1.4^{\circ}$ in group $B$.

Postoperative bone fusion was observed at $10.5 \pm 2.1$ months in group $A$ and at $9.3 \pm 3.1$ months in group $B$, and it was significantly longer in group $A$ than in group $B(p<0.05)$. Although all patients showed complete bone fusion in group $B$, 1 patient in group $A$ required revision surgery due to nonunion, and CT imaging postoperatively showed complete union.

\section{Laboratory Findings}

Mean preoperative ESR was $65.8 \pm 10.5 \mathrm{~mm} / \mathrm{h}$ in group $A$ and $66.8 \pm 11.8 \mathrm{~mm} / \mathrm{h}$ in group $B$, which reduced to normal limits at the final follow-up in both groups. Group A had a mean preoperative CRP of $47.2 \pm 14.6 \mathrm{mg} / \mathrm{L}$, which decreased to $6.5 \pm 3.8 \mathrm{mg} / \mathrm{L}$ at final follow-up, while in group $\mathrm{B}$, mean CRP was $48.1 \pm 14.6 \mathrm{mg} / \mathrm{L}$ preoperatively and decreased to $6.7 \pm$ $4.2 \mathrm{mg} / \mathrm{L}$ at the final visit.

\section{Neurological Status}

In group A, preoperative neurological status of the patients was categorized as grade A in one patient, grade B in one patient, grade $C$ in five patients, and grade $D$ in three patients. At final follow-up, patients with grade $A$ and $B$ neurological status had recovered to grade $E$. Of the five patients with grade $C$ status, 2 reverted to grade $D$, and 3 recovered to grade $E$. In group $B$, 1 patient was evaluated as grade $A$, two patients as grade $C$, and 1 as grade $D$ preoperatively. All patients with neurological deficits returned to normal during the postoperative period.

\section{Postoperative Complications}

Several complications were encountered during the course of postoperative follow-up in both groups. Intraoperative duramater injury in one patient from each group was treated by a consultant neurosurgeon, and two patients in group $B$ developed a hemothorax postoperatively which was treated by a tube thoracostomy. As hardware complications including rod breaking and screw pulling out occurred in one patient from each group, these patients underwent revision surgery. Additionally, postoperative superficial wound infections associated with methicillin-sensitive staphylococcus aureus were successfully treated with antibiotic therapy in two patients. Thus, there were no significant differences in complications between group A and group B ( $p>0.05)$.

\section{- DISCUSSION}

Spinal tuberculosis is a complication of pulmonary tuberculosis, and consultant physicians may have to treat several detrimental complications such as progressive spinal deformity, neurological deficits, and even spinal cord compression during the course of the disease (28). The necessity for surgical intervention in spinal tuberculosis continues to be debated as some authors have suggested that pure spinal tuberculosis, unrelated to significant kyphosis and neurological symptoms, is a medical disease rather than a surgical condition, and that surgery should only be performed in patients with tuberculosis complicated by deformities or/ and paraplegia (16). Conversely, others have advocated that prompt surgical treatment at the onset of disease minimizes neurological involvement and provides excellent neurological results $(23,26)$. In our experience, surgical treatment for all patients with or without significant deformity can be used in the management of Pott's disease as we have observed that, regardless of the type of surgical approach used, i.e., posterior alone or combined, surgery provided a visible resolution of both neurologic deficits and the deformity.

Surgery for spinal tuberculosis aims to remove the focus area, decompress the nerves, correct spinal deformities, provide stable reconstruction, and prevent late onset deformity $(1,14)$. However, the type of surgical procedure that is most suitable for Pott's disease remains disputed (26). Different approaches can be used for the management of spinal tuberculosis, including anterior, combined anterior and posterior, or posterior approach alone $(14,19,27)$. Most reports seem to agree that anterior radical debridement has some advantages over other procedures $(7,15,22,26)$, such as are direct access to lesion site, effective focal debridement, instant recovery due to osseous union, and direct reconstruction of the vertebrae without destruction of the normal posterior elements $(22,25)$. The counter argument is that the procedure is non essential as anterior interbody fusion can be achieved spontaneously without surgery $(8,10,17)$. Interestingly, the findings reported here are consistent with that of previous studies, in that experienced practitioners have stated that the anterior approach is more advantageous than the posterior approach with respect to factors such as direct access to lesion site, greater effective focal debridement, and rapid 
recovery. Further, significant differences in fusion time were observed between the two groups, and these results support the theory that the anterior approach may facilitate faster osseous union. In contrast, the anterior approach carries greater risk of surgical trauma and complications compared to the posterior approach $(31,33)$, and is related to greater blood loss, vascular injury, pulmonary complications such as hemothorax and pleural effusion, and chylous leakage, among others (33). Korkusuz et al. reported a high complication rate of $22 \%$ in patients who had undergone combined anterior debridement and graft placement procedures, including a graft complication rate of $18.3 \%$ and seven deaths during the early postoperative period (11). Chiriano et al. have described a minor vascular injury rate of $24 \%$ and a serious vascular injury rate of $3 \%$ with the anterior approach (4). Similarly, Campbell et al. have suggested that the anterior and the combined anterior and posterior approach had higher complication rates compared to the posterior approach alone (3). As was pointed out above, many authors have sought to debate this issue even though it was generally agreed that the anterior approach was associated with more complications than the posterior approach. In concurrence with previous studies, we show that anterior approach led to more complications than the posterior approach alone, as seen in parameters used for defining invasiveness, namely operation time, length of hospitalization, and intraoperative blood loss.

Due to advances in the treatment of the spinal tuberculosis in the last few years, there has been an increased interest in the posterior approach. Guven et al. have shown that single stage posterior instrumentation and fusion were particularly sufficient for decompression of the spinal cord and drainage of the relevant abscess, especially in patients with posterior element involvement (5). Similarly, Pang et al. and Sahoo et al. have reported remarkably successful outcomes in their studies on the only posterior approach for thoracolumbar spinal tuberculosis $(18,24)$. Nevertheless, contrary to above evidence, Yang et al., in a meta-analysis, have stated that clinical outcomes between posterior and anterior instrumentation are similar (31). Likewise, in a recent study that describeda novel single stage approach to treat spinal tuberculosis, called "the versatile," Srivastava et al. have suggested that anterior debridement and decompression is crucial for neurological recovery if there is anterior column involvement of the spinal tuberculosis. This is because the combined anterior-posterior versatile approach would provide superior neurological outcomes (25). In our facility, initially and prior to using posterior surgery alone, the combined anterior-posterior approach was considered optimal for the management of spinal tuberculosis; however, over the years, our experience has shown that posterior surgery alone would be sufficient for correcting the deformity and for maintaining the correction, both with less surgical trauma. Thus, we have converted our point of view on surgery for Pott's disease and have been performing posterior surgery alone for the past few years.

There area few limitations to this study. First, this was a retrospective study with a small number of patients, which limits the power of the results. Second, the follow-up period in this study was limited to middle-term neurological and radiological outcomes. Therefore, further prospective studies with long-term follow-up in a larger number of patients is required. Lastly, it is possible that the conversion of our surgical management strategy from combined surgery to posterior alone over the years could have led to potential bias in patient outcomes.

\section{CONCLUSION}

The evidence from this study suggests that the combined approach has substantial advantages such as wider surgical area, in-depth debridement, and shorter fusion time. On the other hand, the posterior approach provides comparable clinical efficacy with less operation and hospitalization times, surgical trauma, blood loss, and complication rates. Thus, our results indicate that posterior surgery alone may be a sufficient treatment strategy for spinal tuberculosis, and that the combined anterior-posterior surgery may not be necessary for treatment.

\section{REFERENCES}

1. Abdul-Jabbar A, Takemoto S, Weber MH, Hu SS, Mummaneni PV, Deviren V, Ames CP, Chou D, Weinstein PR, Burch S: Surgical site infection in spinal surgery: Description of surgical and patientbased risk factors for postoperative infection using administrative claims data. Spine 37:1340-1345, 2012

2. Acikgoz B, Ozcan O, Belen D, Erbengi A, Ozgen T: Surgery for progressive Pott's paraplegia (tuberculous paraplegia). Paraplegia 29:537-541, 1991

3. Campbell PG, Malone J, Yadla S, Maltenfort MG, Harrop JS, Sharan AD, Ratliff JK: Early complications related to approach in thoracic and lumbar spine surgery: A single center prospective study. World Neurosurgery 73:395-401, 2010

4. Chiriano J, Abou-Zamzam AM, Urayeneza O, Zhang WW, Cheng $\mathrm{W}$ : The role of the vascular surgeon in anterior retroperitoneal spine exposure: Preservation of open surgical training. Journal of Vascular Surgery 50:148-151, 2009

5. Guven O, Kumano K, Yalcin S, Karahan M, Tsuji S: A single stage posterior approach and rigid fixation for preventing kyphosis in the treatment of spinal tuberculosis. Spine 19:1039-1043, 1994

6. Guzey FK, Emel E, Bas NS, Hacisalihoglu S, Seyithanoglu H, Karacor SE, Ozkan N, Alatas I, Sel B: Thoracic and lumbar tuberculous spondylitis treated by posterior debridement, graft placement, and instrumentation: A retrospective analysis in 19 cases. J Neurosurg Spine 3:450-458, 2005

7. Hodgson A, Stock FE: Anterior spinal fusion a preliminary communication on the radical treatment of Pott's disease and Pott's paraplegia. British Journal of Surgery 44:266-275, 1956

8. Hsu L, Leong J: Tuberculosis of the lower cervical spine (C2 to C7). A report on 40 cases. Bone \& Joint Journal 66:1-5, 1984

9. Kochi A: The global tuberculosis situation and the new control strategy of the World Health Organization. Tubercle 72:1-6, 1991

10. Konstam P, Blesovsky A: The ambulant treatment of spinal tuberculosis. British Journal of Surgery 50:26-38, 1962

11. Korkusuz F, Islam C, Korkusuz Z: Prevention of postoperative late kyphosis in Pott's disease by anterior decompression and intervertebral grafting. World Journal of Surgery 21:524-528, 1997 
12. Kumar $\mathrm{K}$ : The penetration of drugs into the lesions of spinal tuberculosis. International Orthopaedics 16:67-68, 1992

13. Lee CK, Vessa P, Lee JK: Chronic disabling low back pain syndrome caused by internal disc derangements: The results of disc excision and posterior lumbar interbody fusion. Spine 20:356-360, 1995

14. Mak KC, Cheung KM: Surgical treatment of acute TB spondylitis: Indications and outcomes. European Spine Journal 22:603-611, 2013

15. Mehta J, Bhojraj S: Tuberculosis of the thoracic spine. Bone \& Joint Journal 83:859-863, 2001

16. Moon MS: Tuberculosis of the spine: Controversies and a new challenge. Spine 22:1791-1797, 1997

17. Moon MS, Kim I, Woo YK, Park YO: Conservative treatment of tuberculosis of the thoracic and lumbar spine in adults and children. International Orthopaedics 11:315-322, 1987

18. Pang X, Shen X, Wu P, Luo C, Xu Z, Wang X: Thoracolumbar spinal tuberculosis with psoas abscesses treated by one-stage posterior transforaminal lumbar debridement, interbody fusion, posterior instrumentation, and postural drainage. Archives of Orthopaedic and Trauma Surgery 133:765-772, 2013

19. Pola E, Rossi B, Nasto LA, Colangelo D, Logroscino CA: Surgical treatment of tuberculous spondylodiscitis. Eur Rev Med Pharmacol Sci 16:79-85, 2012

20. Polley P, Dunn R: Noncontiguous spinal tuberculosis: Incidence and management. European Spine Journal 18:1096-1101, 2009

21. Rajasekaran S: The natural history of post-tubercular kyphosis in children: Radiological signs which predict late increase in deformity. J Bone Joint Surg 83B:954-962, 2001

22. Rajasekaran S, Soundarapandian S: Progression of kyphosis in tuberculosis of the spine treated by anterior arthrodesis. J Bone Joint Surg Am 71:1314-1323, 1989

23. Rezai AR, Lee M, Cooper PR, Errico TJ, Koslow M: Modern management of spinal tuberculosis. Neurosurgery 36:87-98, 1995

24. Sahoo MM, Mahapatra SK, Sethi GC, Dash SK: Posterioronly approach surgery for fixation and decompression of thoracolumbar spinal tuberculosis: A retrospective study. Clinical Spine Surgery 25:E217-E223, 2012
25. Srivastava SK, Aggarwal RA, Bhosale SK, Roy K, Nemade PS: The versatile approach: A novel single incision combined with anterior and posterior approaches for decompression and instrumented fusion to treat tuberculosis of the thoracic spine. Asian Spine Journal 11:294-304, 2017

26. Turgut M: Spinal tuberculosis (Pott's disease): Its clinical presentation, surgical management, and outcome. A survey study on 694 patients. Neurosurgical Review 24:8-13, 2001

27. Varatharajah S, Charles YP, Buy X, Walter A, Steib JP: Update on the surgical management of Pott's disease. Orthop Traumatol Surg Res 100:229-235, 2014

28. Wang Y, Wang Q, Zhu R, Yang C, Chen Z, Bai Y, Li M, Zhai X: Trends of spinal tuberculosis research (1994-2015): A bibliometric study. Medicine (Baltimore) 95(38):e4923, 2016

29. Wang YX, Zhang HQ, Li M, Tang MX, Guo CF, Deng A, Gao Q, Wu JH, Liu JY: Debridement, interbody graft using titanium mesh cages, posterior instrumentation and fusion in the surgical treatment of multilevel noncontiguous spinal tuberculosis in elderly patients via a posterior-only. Injury 48(2):378-383, 2017

30. Wang Z, Yuan H, Geng G, Shi J, Jin W: Posterior mono-segmental fixation, combined with anterior debridement and strut graft, for treatment of the mono-segmental lumbar spine tuberculosis. International Orthopaedics 36:325-329, 2012

31. Yang P, He X, Li H, Zang Q, Yang B: Clinical efficacy of posterior versus anterior instrumentation for the treatment of spinal tuberculosis in adults: A meta-analysis. J Orthop Surg Res 9(1):10, 2014

32. Zhang HQ, Li JS, Zhao SS, Shao YX, Liu SH, Gao Q, Lin MZ, Liu JY, Wu JH, Chen J: Surgical management for thoracic spinal tuberculosis in the elderly: Posterior only versus combined posterior and anterior approaches. Archives of Orthopaedic and Trauma Surgery 132:1717-1723, 2012

33. Zhang P, Peng W, Wang X, Luo C, Xu Z, Zeng H, Liu Z, Zhang $\mathrm{Y}$, Ge L: Minimum 5-year follow-up outcomes for single-stage transpedicular debridement, posterior instrumentation and fusion in the management of thoracic and thoracolumbar spinal tuberculosis in adults. British Journal of Neurosurgery 30:666671,2016 